\title{
Multiple myeloma in Korea: past, present, and future perspectives. Experience of the Korean Multiple Myeloma Working Party
}

\author{
Jae Hoon Lee $\cdot$ Dong Soon Lee $\cdot$ Je Jung Lee $\cdot$ Yoon Hwan Chang $\cdot$ Jong Youl Jin $\cdot$ \\ Deog-Yeon Jo $\cdot$ Soo Mee Bang $\cdot$ Hyo Jung Kim · Jin Seok Kim $\cdot$ Kihyun Kim • \\ Hyeon Seok Eom • Chang Ki Min · Sung Soo Yoon - Sun Hee Kim - Cheolwon Suh • \\ Kyung Sam Cho $\cdot$ the Korean Multiple Myeloma Working Party (KMMWP)
}

Received: 24 May 2010/Accepted: 25 May 2010/Published online: 11 June 2010

(c) The Japanese Society of Hematology 2010

The incidence of multiple myeloma suggests an ethnic difference. Compared to Caucasians, who have an incidence rate of 3-5/100,000, Asians show much lower incidence rate compared to them, in the range of $0.5-3 / 100,000$. In Korea, The very first case report of multiple myeloma was published in 1959 [1], and was followed by a few case reports until the 1970s. Since that time, the number of cases of multiple myeloma in Korea increased steadily, reaching 100 cases/year in 1990 [2] and 500 cases/year in 2000 [3],

\section{J. H. Lee $(\bowtie)$}

Department of Internal Medicine,

Gachon University Gil Hospital, 1198 Guwol-dong,

Namdong-gu, Incheon 405-220, Korea

e-mail: jhlee@gilhospital.com

\section{S. Lee}

Department of Laboratory Medicine,

Seoul National University Hospital, Seoul, Korea

e-mail: soonlee@plaza.snu.ac.kr

\section{J. J. Lee}

Department of Hematology,

Chonnam University Hwasun Hospital, Hwasun, Korea

e-mail: drjejung@chonnam.ac.kr

\section{Y. H. Chang}

Department of Laboratory Medicine,

Korea Cancer Center Hospital, Seoul, Korea

e-mail: cyhlabo@kcch.re.kr

J. Y. Jin

Department of Internal Medicine,

Bucheon St Mary's Hospital, Bucheon, Korea

e-mail: drjin@catholic.ac.kr

D.-Y. Jo

Department of Internal Medicine,

Chungnam National University Hospital, Daejeon, Korea

e-mail: deogyeon@cnu.ac.kr and it is still going up. Currently in Korea, 1,000 patients are estimated to be diagnosed with multiple myeloma, and 700 patients are assumed to die of this disease every year, and $4,000-5,000$ patients are suffering from this disease [4]. The most updated, age-standardized, incidence rate of multiple myeloma in Korea is $1.4 / 100,000$, and ranked as the third most common among the hematologic malignancies, only surpassed by non-Hodgkin's lymphoma and acute myeloid leukemia [5]. Besides, the mortality from multiple myeloma

\author{
S. M. Bang \\ Department of Internal Medicine, \\ Seoul National University Bundang Hospital, \\ Seongnam, Korea \\ e-mail: smbang7@snu.ac.kr \\ H. J. Kim \\ Department of Internal Medicine, \\ Hallym University Sacred Heart Hospital, Anyang, Korea \\ e-mail: hemonc@hanmail.net \\ J. S. Kim \\ Division of Hematology, Department of Internal Medicine, \\ Yonsei University College of Medicine, Seoul, Korea \\ e-mail: hemakim@yuhs.ac \\ K. Kim \\ Department of Medicine, Samsung Medical Center, \\ Sungkyunkwan University School of Medicine, Seoul, Korea \\ e-mail: kihyunk@skku.edu \\ H. S. Eom \\ Hematology-Oncology Clinic, National Cancer Center, \\ Goyang, Korea \\ e-mail: hseom@ncc.re.kr \\ C. K. Min \\ Department of Internal Medicine, St. Mary's Hospital, \\ Seoul, Korea \\ e-mail: ckmin@catholic.ac.kr
}


has remarkably increased compared with the mortalities from the other hematologic malignancies, such as leukemia and lymphoma. Indeed, the incidence and mortality of multiple myeloma in Korea have increased more than 30 times during past 30 years [5] (Fig. 1). This unprecedented phenomenon could be explained in two ways. The first one is an increased detection. Expanding medical insurance coverage increased routine checks, and increased awareness of this disease could partly explain in the increased detection, especially in early period of 1980s. The second explanation is a true increase in the incidence of multiple myeloma. Air pollution, and increased exposure to potential carcinogens and radiation are all associated with rapid industrialization, and are suspected as reasons for the increased incidence of multiple myeloma. Another possible reason for the increase is the aging of the Korean population. Koreans have experienced a 17-year median life span over the past 33 years. Since the year of 2,000, Koreans entered an aging society and are heading to an aged society in the year 2020. Moreover, the speed of aging in Korea is known to be fastest in the world. Thus, in the future, we expect more increasing aged population and the incidence of multiple myeloma, considering Japanese model [5]. The median age of the patients with multiple myeloma also increased from mid-fifties in 1980s to 66 years in 2007 [3].

There have been 3 important advances in the treatment of multiple myeloma. The first one was an emergence of effective chemotherapy using alkylating agents in the early 1960s. The second was an introduction of high-dose therapy (HDT) with stem cell supports in the 1980s, and the third was the advent of targeted agents in 2000s. In the era of conventional chemotherapy, Korean hematologists had to conduct small scale, both prospective and retrospective studies, single center studies that were written in Korean and

\section{S. S. Yoon}

Department of Internal Medicine,

Seoul National University Hospital, Seoul, Korea

e-mail: ssysmc@snu.ac.kr

\section{S. H. Kim}

Department of Laboratory Medicine and Genetics,

Samsung Medical Center, Sungkyunkwan

University School of Medicine, Seoul, Korea

e-mail: sunnyhk@skku.edu

C. Suh

Department of Internal Medicine, Asan Medical Center,

Seoul, Korea

e-mail: csuh@amc.seoul.kr

K. S. Cho

Department of Hematology-Oncology,

Kyung Hee University Hospital, Seoul, Korea

e-mail: ksamcho@khmc.or.kr

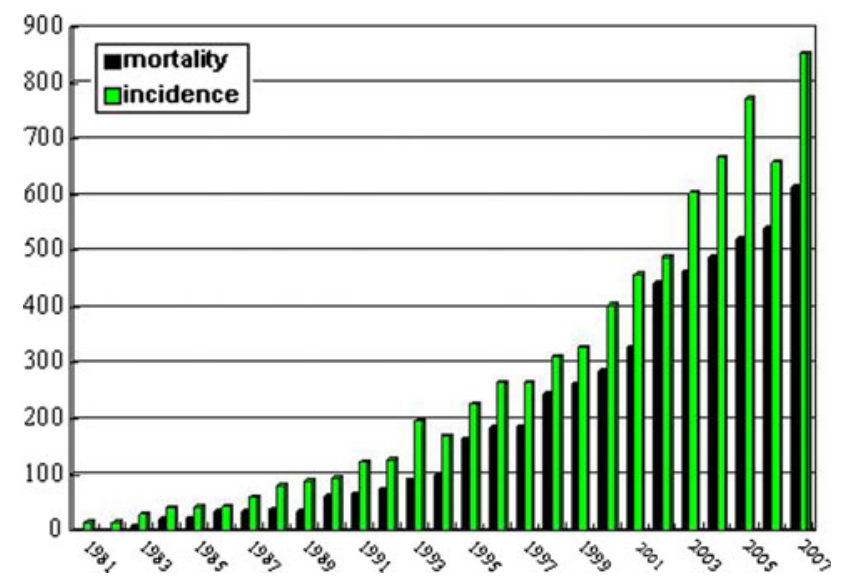

Fig. 1 Changes of incidence and mortality of multiple myeloma over 30 years in Korea

published in domestic journals. Because multiple myeloma was a relatively rare disease in Korea at that time, it was not easy for a single institute to enroll enough patients into even small phase 2 trials. At times, it took a sometimes more than 5 years, to finish small phase 2 studies even in relatively large hospitals. These studies were simple repeats of Western studies testing the efficacy such of melphalan with prednisone (MP), multi-drug combinations such as M2 protocol [vincristine, carmustine, cyclophosphamide, melphalan, and prednisone (VBCMP)], vincristine with doxorubicin and dexamethasone(VAD) or merely reporting clinical features. The treatment results were almost the same or slightly inferior to Western studies because the patients tended to be diagnosed later in their course of disease [6-13]. There was no room for new drug trials or creative new combination using the existing drugs. Besides, it was before the emergence of official organization or motivated hematologist to conduct multicenter trials. It was only during the era of HDT with autologous stem cell transplantation (ASCT) we realized that multi-center trials are the only way to overcome the problems of a small number of the patients. The emergence of small study groups based on geographic distribution or personal acquaintance occurred spontaneously. These groups began to conduct small-scale multi-center studies of HDT with ASCT, initially as a retrospective study testing the feasibility of HDT with ASCT [14], followed by prospective trials [15]. Later, more sophisticated prospective trials based on cytogenetics including FISH and serum beta2-microglobulin [16], in which allogeneic transplantation is included for high-risk subgroup, were attempted. Multicenter trials for basic studies in myeloma physiology also began [17]. Small retrospective studies on the efficacy of novel agents such as bortezomib [18] or thalidomide [19] in patients with refractory or relapsed myeloma were also conducted. However, these trials were still not nationwide studies. 
The Korean Society of Hematology (KSH) which celebrated its 50th anniversary in 2008 decided to launch official study groups in 2005; these study groups were working parties for major hematologic diseases. The Korean Multiple Myeloma Working Party (KMMWP) which began in November 2005 was one of the 11 working parties launched under the auspices of the KSH. KMMWP immediately began a retrospective study on the toxicities of bortezomib in Korean population; this study had never before been published in Asians [20]. Bortezomib toxicities, whose profiles were similar to Western data, were reported. The most commonly observed toxicities were thrombocytopenia (47\%) and sensory neuropathy (42\%), while the gastrointestinal toxicities were reported lower than Western data. The comparison of various myeloma staging systems in predicting the efficacy of HDT was also published [21]. The Southwest Oncology Group (SWOG) staging system and International Staging System (ISS) at diagnosis were able to predict progression-free survival (PFS) as well as overall survival (OS) after HDT with ASCT, but the Durie-Salmon system (DSS) was not. We collected bone marrow samples of Korean myeloma patients, and performed cytogenetic study in the central laboratory. We published cytogenetic characteristics of Korean patients with multiple myeloma using FISH technique [22]. We found that $13 \mathrm{q}$ deletion (45.6\%), $\mathrm{IgH}$ translocation $(41 \%)$, and 1q gain $(38.8 \%)$ were the most common cytogenetic aberrations in Korean patients with multiple myeloma.

The KMMWP immediately began prospective multicenter trials testing the efficacy of targeted agents such as bortezomib or thalidomide in relapsed myeloma [23, 24] as well as in newly diagnosed myeloma either in transplantation candidates $[25,26]$ or in non-transplant candidates [27]. Approximately 20 institutes have participated in each study. These protocols were registered to the National Institute Of Health (NIH) of USA (http://ClinTrials.gov), and were posted to the website of the Multiple Myeloma Research Foundation (MMRF). These were conducted for the first time under strict monitoring in Korean hematology study history. All of these studies showed very high response rates with acceptable toxicities, confirming the high efficacy of novel agents in the treatment of multiple myeloma.

In salvage setting, 6 cycles of bortezomib with doxorubicin and dexamethasone (PAD) followed by 12 cycles of thalidomide with dexamethasone (TD) consolidation resulted in a very high response rate (RR) of $83.6 \%$ including $51.4 \%$ complete response (CR), $13.4 \%$ near complete response (nCR), $5.4 \%$ very good partial response (VGPR), and $13.4 \%$ partial response (PR) [23] by modified EBMT criteria with additional categories of $\mathrm{nCR}$ and VGPR. With the median follow-up of 27 months (range
13-39 months), the median PFS was 18 months (95\% CI 9.7-26.2 months), with a 1-year PFS rate 56.9\% and 3-year PFS rate $25.7 \%$. Median OS was 35.1 months $(95 \%$ CI 18.5-51.7 months), 1-year survival rate $75 \%$ and 3 -year survival rate $27.3 \%$. We also studied the efficacy and safety of a four-drug combination of bortezomib, cyclophosphamide, thalidomide, and dexamethasone (Vel-CTD) for patients with relapsed or refractory multiple myeloma [24]. The overall best response rate was $87.2 \%$, with $45.7 \%$ CR 8.6\% VGPR, and $32.9 \%$ PR. After a median follow-up of 12.6 months, the median PFS was 14.6 months and the 3 -year PFS was $14.5 \%$. The median OS was 31.6 months and the 3 -year OS was $47.2 \%$. These 2 trials showed very high response rates in salvage setting. The reason for this high response is not easily explainable. This could be explained as selection bias. However, these high responses were not durable and were not translated into improved survival.

In the front-line treatment setting for transplant candidates, 2 cycles of bortezomib (Velcade) with thalidomide and dexamethasone (VTD) followed by 2 cycles of the classic vincristine with doxorubicin and dexamethasone (VAD) regimen resulted in $96 \%$ response rate including $28 \% \mathrm{CR}+\mathrm{nCR}$ before HDT [25]. In another study, 4 cycles of cyclophosphamide with thalidomide and dexamethasone (CTD) also resulted in $86.5 \% \mathrm{RR}$ including $38 \%$ CR [25]. For the transplant-ineligible patients, 6 cycles of bortezomib with thalidomide and dexamethasone (VTD) induction therapy followed by 8 cycles of melphalan with thalidomide and prednisone (MPT) consolidation resulted in $95 \% \mathrm{RR}$, including $74 \% \mathrm{CR}, 5 \% \mathrm{nCR}$, $11 \%$ VGPR, 5\% PR, and 5\% progressive disease (PD) [27].

These were the first studies reporting the efficacy of targeted agents as front-line therapies in an Asian area. These trials used the analysis of the cytogenetics using both conventional cytogenetics and FISH in the central laboratory. We built bone marrow sample delivery system for these trials. We realized the importance of sharing clinical samples as well as ideas for basic studies on myeloma. Serial multicenter basic studies have been done on the incidence of genetic polymorphisms of NQO1 gene [28] and CYPA1 gene [29] that can, at least partly, explain the relatively lower genetic susceptibility of myeloma in the Asian population, antagonistic interaction of polyphenols on bortezomib treatment [30], incidence of interleukin-6 receptor gene (IL6R) amplification [31], and its implication in the prognosis of MM, and methylation profiles of $p 14, p 15$, and $p 15$ gene and its prognostic implications in MM [32].

Next, we constructed the Korean Myeloma Registry (KMR), a web-based patient registry system. Currently, more than 4,000 patients who were diagnosed after the year of 2,000 are registered from 41 institutes. We have documented the basic feature of this population [33]. 
The median age was 64 years, and there is a slight male predominance. The ISS I/II/III score were 17,31 , and $39 \%$, respectively. The median survival time was 50 months, and was well delineated by the ISS. Based on registry data, we already completed some retrospective multi-center studies. We analyzed the importance of attaining CR before HDT [34]. Patients who achieved CR before HDT (continued $\mathrm{CR}$ ) had significantly higher survival rate than patients who achieved CR only after HDT (induced CR) $(P=0.018)$ We compared the results of reduced intensity stem cell transplantation (RIST) following autotransplant versus tandem autotransplant [35]. There was no significant difference in the event-free survival (EFS) $(P=0.26)$, OS $(P=0.13)$, treatment-related mortality (TRM, $P=0.35$ ), and disease-related mortality (DRM, $P=0.33$ ) between ASCT/RIST group $(n=30)$ and tandem ASCT group $(n=126)$. We also analyzed the survival difference between the tandem ASCT group versus the single ASCT retrospectively [36]. We found that tandem transplant is an independent prognostic factor for PFS $(P=0.002)$ and OS $(P=0.044)$ in our patient population.

We studied the incidence of herpes zoster reactivation after treatment with bortezomib [37]. In our study, 22\% out of 267 patients suffered from Varicella zoster reactivation. We also performed retrospective studies showing the incidence of thromboembolic complications with thalidomide use in Korean patients [38]. In that study, only 3.9\% out of 360 Korean patients developed arterial or venous thrombosis. This rate was apparently lower compared to Western study of a Caucasian population, implying an ethnic difference of susceptibility to thromboembolism. We also compared the various induction regimens before autotransplant [39]. Bortezomib seemed to induce high rate of CRs compared to the other induction regimens. We published the cytogenetic characteristics of Korean myeloma patients as previously described [22]. A similar study was performed in Waldenstrom macroglobulinemia (WM) this year [40]. We found the difference in cytogenetic characteristics between MM and WM. We also discovered subtle difference between our data and Western data.

In the field of immunotherapy, antigen-presenting cells with increased potency, such as dendritic cells (DCs) or CD40-activated B cells [41, 42], were investigated by members of KMMWP. They reported the possibility of immunotherapy for MM with the use of myeloma-specific cytotoxic T lymphocytes (CTLs) that were stimulated in vitro by DCs pulsed with purified and optimized myeloma lysates [41]. The defective function of DCs in patients with MM was significantly affected by loading tumor antigens, and neutralization of VEGF could overcome this DC dysfunction through the elimination of abnormal signal transduction [43]. In addition, autologous DCs loaded with allogeneic myeloma cells can generate potent myeloma-specific CTL responses against autologous myeloma cells [44]. On the basis of these bench works, they are going to perform a clinical trial using potent DCs in patients with MM.

At last year's American Society of Hematology (ASH) meetings, we presented several retrospective studies such as clinical presentation of IgD myeloma [45], malignant pleural effusions of multiple myeloma [46], osteonecrosis of jaw [47], the FISH characteristics and survival [48], and the effect of bortezomib on bone metabolism [49].

In the past, due to the low incidence of multiple myeloma and other obstacles, we were not able to conduct high-quality studies. However, the changes described above made us able to present dozens of abstracts at international meetings such as International Myeloma Workshop (IMW), ASH, and European Hematology Association (EHA), etc. Most of the studies presented as abstracts were already published in peer-reviewed journals.

In 2009, we participated in 2 important global project of international myeloma working group, a FISH study and historical control project [50, 51]. KMMWP supplied substantial number of cases from Asia to these global trials. We also began to participate in the review articles of International Myeloma Working Group (IMWG) such as treatment guideline from 2009 [52].

In 2010, a few important sponsor initiated global clinical trials (SIT) of novel agents (velcade, revlimid, vorinostat, panobinostat, tanespimycin, masitinib: Vantage, First, Panorama-1 Study, etc.) were launched in Korea as well as investigator-initiated trials (IITs) such as Revlimid monotherapy for standard risk MM, shared with the Moffitt Cancer Center, USA. Moreover, a dozen of prospective studies (KMM93, KMM94, and KMM97) and retrospective studies (KMM95, KMM96, KMM101-107) of our own are ongoing. With these studies, we would like to provide new drug use opportunities to our patients as well as to contribute to the society of multiple myeloma research.

The KMMWP has been holding patient- and familysupporting seminars annually since it held the first seminar at 2006 joined by International Myeloma Foundation (IMF). Besides, more than a dozen of myeloma experts from all around the world visited Korea by its invitation. Also KMMWP is seeking for regional collaborations with Asian countries such as joint conference with Japanese Myeloma Study Group (JMSG).

Hopefully, the research activities on multiple myeloma in Asian countries will soon intensify, move toward the main stage of the world, and compete with US or European groups. There are ongoing activities for the establishing of national myeloma study groups in Asian countries. Some of the groups may experience the same thing we faced few years ago. We would like to share our experience with them for the proliferation of Asia myeloma study. 


\section{References}

1. Lee H, Lee M. A case of alpha2 plasmacytoma. New Med J. 1959;2:1113-7.

2. Yang SH, Kim TY, Kim BK, Koh YW, Kwak DS, Kim NK, et al. A statistical study of multiple myeloma in Korea. Korean $\mathbf{J}$ Hematol. 1995;30:345-61.

3. Annual report of the Korea Central Cancer Registry. Korea Central Cancer Registry, Ministry of Health and Welfare Republic of Korea. 2007. http://www.ncc.re.kr/.

4. Korean Health Insurance Review Agency. 2008 health insurance review and evaluation statistical yearbook. 2008. http://www.hira.or.kr/.

5. Lee JH, Bang SM. Epidemiological changes of multiple myeloma in Korea. Korean J Hematol. 2006;41:225-34.

6. Kang DY, Lee DI, Kim KH, Kim DJ, Kim BS, Kim SI, et al. Statistical studies on multiple myeloma in Korea-preliminary report. Korean J Hematol. 1972;7:31-40.

7. Kim HJ, Heo DS, Bang YJ, Lee SJ, Choi DH, Park S, et al. Multiple myeloma in Korea-clinical analysis and treatment results in 61 cases. Korean J Int Med. 1984;28:770-8.

8. Kim TY, Heo DS, Bang YJ, Park S, Kim BK, Kim NK, et al. Combination chemotherapy with vincristine, melphalan and prednisone for multiple myeloma. Korean J Int Med. 1993;45:1-12.

9. Kim HJ, Seo CI, Park KC, Kim HT, Heo DS, Bang YJ, et al. Combination chemotherapy for the treatment of multiple myeloma. J Korean Cancer Assoc. 1992;24:577-85.

10. Jung JW, Kim JH, Kim SY, Yoon HJ, Cho KS. A clinical study on multiple myeloma. J Korean Cancer Assoc. 1995;27:869-78.

11. Lee JT, Kim IH, Ahn JS, Lee KH, Kim TY, Park YI, et al. Phase II trial of VAD (vincristine, doxorubicin, and dexamethasone) in refractory multiple myeloma. Korean $\mathbf{J}$ Hematol. 1996;31:145-53.

12. Lee EJ, Lee KH, Hyun MS. Clinical characteristics and therapeutic results in multiple myeloma. Korean $\mathbf{J}$ Hematol. 1997;32:409-18.

13. Kim SW, Ryoo BY, Kim TY, Im YH, Park YH, Kim BS, et al. A phase II trial of VAD (vincristine, doxorubicin and dexamethasone) chemotherapy for previously untreated multiple myeloma. Korean J Int Med. 1999;56:75-84.

14. Lee JH, Bang SM, Lee S, Kim HS, Ahn JS, Cho EK, et al. High dose chemotherapy with autologous stem cell transplantation in multiple myeloma. Korean J of Hematol. 1999;34:306-16.

15. Bang SM, Lee JH, Yoon SS, Seong JM, Cho KS, Kang YG, et al. High dose therapy followed by autologous peripheral blood stem cell transplantation as a first line treatment for multiple myeloma. J Korean Med Sci. 2003;18:673-8.

16. Bang SM, Lee JH, Yoon SS, Park S, Lee JJ, Kim HJ, Jo DY, et al. Preliminary report of risk-based approach in Korean patients with newly diagnosed multiple myeloma. Blood. 2004;104:4911.

17. Oh HS, Lee JH, Ahn MJ, Chung CW, Lee SI, Park Q, et al. Comparison of microvessel density before and after peripheral blood stem cell transplantation in multiple myeloma patients and its clinical implications: multicenter trial. Int $\mathbf{J}$ Hematol. 2002;76:465-70.

18. Lee KW, Yun T, Song EK, Na II, Shin H, Bang SM, et al. A pilot study of bortezomib in Korean patients with relapsed or refractory myeloma. J Korean Med Sci. 2005;20:598-602.

19. Kim DY, Im SA, Seong CM, Lee SN, Lee JH, Bang SM, et al. Salvage therapy with thalidomide in patients with multiple myeloma. Korean J Hematol. 2002;37:259-64.

20. Bang SM, Lee JH, Yoon SS, Park S, Min CK, Kim CC, et al. A multicenter retrospective analysis of adverse events in Korean patients using bortezomib for multiple myeloma. Int J Hematol. 2006;83:309-13.
21. Kim H, Sohn HJ, Kim S, Kim K, Lee JH, Bang SM, et al. New staging systems can predict prognosis of multiple myeloma patients undergoing autologous peripheral blood stem cell transplantation as first-line therapy. Biol Blood Marrow Transplant. 2006;12:837-44.

22. Bang SM, Kim YR, Cho HI, Chi HS, Seo EJ, Park CK, et al. Identification of $13 \mathrm{q}$ deletion, trisomy $1 \mathrm{q}$, and $\mathrm{IgH}$ rearrangement as the most frequent chromosomal changes found in Korean patients with multiple myeloma. Cancer Genet Cytogenet. 2006;168:124-32.

23. Lee SS, Suh C, Kim BS, Chung J, Joo YD, Ryoo HM, et al. Bortezomib, doxorubicin and dexamethasone (PAD) combination therapy followed by thalidomide and dexamethasone (TD) as a salvage treatment for relapsed multiple myeloma (MM): preliminary analysis of efficacy and safety. the Korean Multiple Myeloma Working Party (KMMWP). Ann Hematol. 2010 [Epub ahead of print] (English).

24. Kim YK, Sohn SK, Lee JH, Yang DH, Moon JH, Ahn JS, et al. Clinical efficacy of a bortezomib, cyclophosphamide, thalidomide, and dexamethasone (Vel-CTD) regimen in patients with relapsed or refractory multiple myeloma: a phase II study. Ann Hematol. 2010;89:475-82.

25. Yoon SS, Kim HJ, Lee JH, Lee DS, Eom HS, Jang JH, et al. Sequential VAD (vincristine, adriamycin, dexamethasone) and VTD (VELCADE ${ }^{\circledR}$, thalidomide, dexamethasone) induction followed by high-dose therapy with autologous stem cell transplantation and maintenance treatment with VELCADE for newly diagnosed multiple myeloma: interim results of phase II trial. The Korean Multiple Myeloma Working Party (KMMWP). Blood. 2007;110:952 (ASH Annual Meeting Abstracts).

26. Yang DH, Kim YK, Sohn SK, Chung JS, Joo YD, Lee JH, et al. Induction treatment with cyclophosphamide, thalidomide, and dexamethasone in newly diagnosed multiple myeloma: a phase II study. Clin Lymphoma Myeloma Leuk. 2010;10:62-7.

27. Eom HS, Kim YK, Chung JS, Kim K, Kim HJ, Kim HY, et al. Bortezomib, thalidomide, dexamethasone induction therapy followed by melphalan, prednisolone, thalidomide consolidation therapy as a first line of treatment for patients with multiple myeloma who are non-transplant candidates: results of the Korean Multiple Myeloma Working Party (KMMWP). Ann Hematol. 2010;89:489-97.

28. Kang SH, Kim TY, Kim HY, Lee YK, Moon HW, Lee DS, et al. Association of NQO1 polymorphism with multiple myeloma risk in Korea. Korean J Lab Med. 2006;26:71-6.

29. Kang SH, Kim TY, Kim HY, Yoon JH, Cho HI, Yoon SS, et al. Protective Role of CYP1A1*2A in the development of multiple myeloma. Acta Hematol. 2008;119:60-4.

30. Kim TY, Park J, Oh B, Min HJ, Jeong TS, Lee JH, et al. Natural polyphenols antagonize the antimyeloma activity of proteasome inhibitor bortezomib by direct chemical interaction. Br J Haematol. 2009;146:270-81.

31. Min HJ, Kim TY, Oh B, Lee JH, Lee DS. The assessment of IL-6R gene using FISH in MM. Blood. 2007;110:4849 (ASH Annual Meeting Abstracts).

32. Kang SH, Lee DS, Kim TY, Min HJ, Oh B, Cho HI, et al. Methylation profiles of p16, p15 and p14 genes in Korean patients with multiple myeloma. Blood. 2007;110:1504 (ASH Annual Meeting Abstracts).

33. Kim SJ, Kim K, Kim BS, Jo DY, Kang HJ, Kim JS, et al. Clinical features and survival outcomes in patients with multiple myeloma: analysis of web-based data from the Korean Myeloma Registry. Acta Hematol. 2009;122:200-10.

34. Kim JS, Kim K, Cheong JW, Min YH, Suh C, Kim H, et al. Complete remission status before autologous stem cell transplantation is an important prognostic factor in patients with 
multiple myeloma undergoing upfront single autologous transplantation. Biol Blood Marrow Transplant. 2009;15:463-70.

35. Min CK, Kim H, Kim K, Kwak JY, Lee ST, Won JH, et al. A multicenter comparison of autologous stem cell transplantation followed by reduced-intensity allogeneic stem cell transplantation with tandem autologous stem cell transplantation in multiple myeloma. Blood. 2007;110:940 (ASH Annual Meeting Abstracts).

36. Sym SJ, Kwak JY, Min CK, Won JH, Lee ST, Kim K, et al. Single and tandem autologous peripheral blood stem cell transplantation for patients with multiple myeloma: a korean multicenter retrospective study. Blood. 2007;110:5132 (ASH Annual Meeting Abstracts).

37. Kim SJ, Kim K, Kim BS, Lee HJ, Kim H, Lee NR, et al. Bortezomib and the increased incidence of herpes zoster in patients with multiple myeloma. Clin Lymphoma Myeloma Leuk. 2008;8:237-40.

38. Koh Y, Bang SM, Lee JH, Yoon HJ, Do YR, Ryoo HM, et al. Low incidence of clinically apparent thromboembolism in Korean patients with multiple myeloma treated with thalidomide. Ann Hematol. 2010;89:201-6.

39. Kim SJ, Kim K, Lee JH, Kim MK, Kwak JY, Ryoo HM, et al. Bortezomib-based induction therapy induces better responses and outcomes of autologous stem cell transplantation in newly diagnosed patients with multiple myeloma: the results of Korean Multiple Myeloma Working Party retrospective study, KMM84. Blood. 2008;112:5184.

40. Bang SM, Seo JW, Park KU, Kim SJ, Kim K, Kim SH, et al. Molecular cytogenetic analysis of Korean patients with Waldenström macroglobulinemia. Cancer Genet Cytogenet. 2010;197:117-21.

41. Lee JJ, Choi BH, Kang HK, Park MS, Park JS, Kim SK, et al. Induction of multiple myeloma-specific cytotoxic $\mathrm{T}$ lymphocyte stimulation by dendritic cell pulsing with purified and optimized myeloma cell lysates. Leuk Lymphoma. 2007;48:2022-31.

42. Kim SK, Nguyen Pham TN, Nguyen Hoang TM, Kang HK, Jin $\mathrm{CJ}$, Nam $\mathrm{JH}$, et al. Induction of myeloma-specific cytotoxic $\mathrm{T}$ lymphocytes ex vivo by CD40-activated B cells loaded with myeloma tumor antigens. Ann Hematol. 2009;88:1113-23.

43. Yang DH, Park JS, Jin CJ, Kang HK, Nam JH, Rhee JH, et al. The dysfunction and abnormal signaling pathway of dendritic cells loaded by tumor antigen can be overcome by neutralizing VEGF in multiple myeloma. Leuk Res. 2009;33:665-70.
44. Yang DH, Kim MH, Hong CY, Lee YK, Jin CJ, Pham TN, et al. Alpha-type 1-polarized dendritic cells loaded with apoptotic allogeneic myeloma cell line induce strong CTL responses against autologous myeloma cells. Ann Hematol. 2010 [Epub ahead of print].

45. Kim MK, Suh C, Min CK, Kim JS, Kim K, Moon JH, et al. Immunoglobulin D multiple myeloma: clinical presentation, response to therapy and prognostic factors in 75 patients: an analysis of the Korean Multiple Myeloma Working Party (KMMWP). Blood. 2009;114:1792 (ASH Annual Meeting Abstracts).

46. Kim HJ, Choi DR, Yun GW, Park EK, Kim SJ, Lee YK, et al. Myelomatous pleural effusion of multiple myeloma: characteristics and outcome. Blood. 2009;114:3874 (ASH Annual Meeting Abstracts).

47. Kim HJ, Shim H, Park EK, Kim MK, Kim SJ, Park JS, et al. Osteonecrosis of the jaw in multiple myeloma patients: incidence and characteristics in Korean patients. Blood. 2009;114:4956 (ASH Annual Meeting Abstracts).

48. Kim MJ, Oh SJ, Min CK, Park CW, Yoon HJ, Do YR, et al. The prognostic impact of fluorescent-in situ hybridization (FISH) and conventional karyotyping in Korean multiple myeloma patients: a retrospective multicenter study. Blood. 2009;114:4902 (ASH Annual Meeting Abstracts).

49. Min CK, Kim SJ, Lee JJ, Suh C, Kim JS, Yoon SS, et al. The effect of bortezomib on bone metabolism of patients with multiple myeloma: a Korean multicenter prospective study. Blood. 2009;114:4871 (ASH Annual Meeting Abstracts).

50. Avet-Loiseau H, Durie BGM, Haessler J, Crowley J, Hoering A, Barlogie B, et al. Impact of FISH and cytogenetics on overall and event free survival in myeloma: an IMWG analysis of 9,897 patients. Blood. 2009;114:743 (ASH Annual Meeting Abstracts).

51. Kumar S, Crowley J, Goldschmidt H, Hoering A, Jagannath S, Lahuerta JJ, et al. Natural history of multiple myeloma relapsing after therapy with IMiDs and bortezomib: a multicenter International Myeloma Working Group Study. Blood. 2009;114:2878 (ASH Annual Meeting Abstracts).

52. Palumbo A, Sezer O, Kyle R, Miguel JS, Orlowski RZ, Moreau $\mathrm{P}$, et al. International Myeloma Working Group guidelines for the management of multiple myeloma patients ineligible for standard high-dose chemotherapy with autologous stem cell transplantation. Leukemia. 2009;23:1716-30. 